\section{LA-13537-MS}

Approved for public release;

distribution is unlimited.

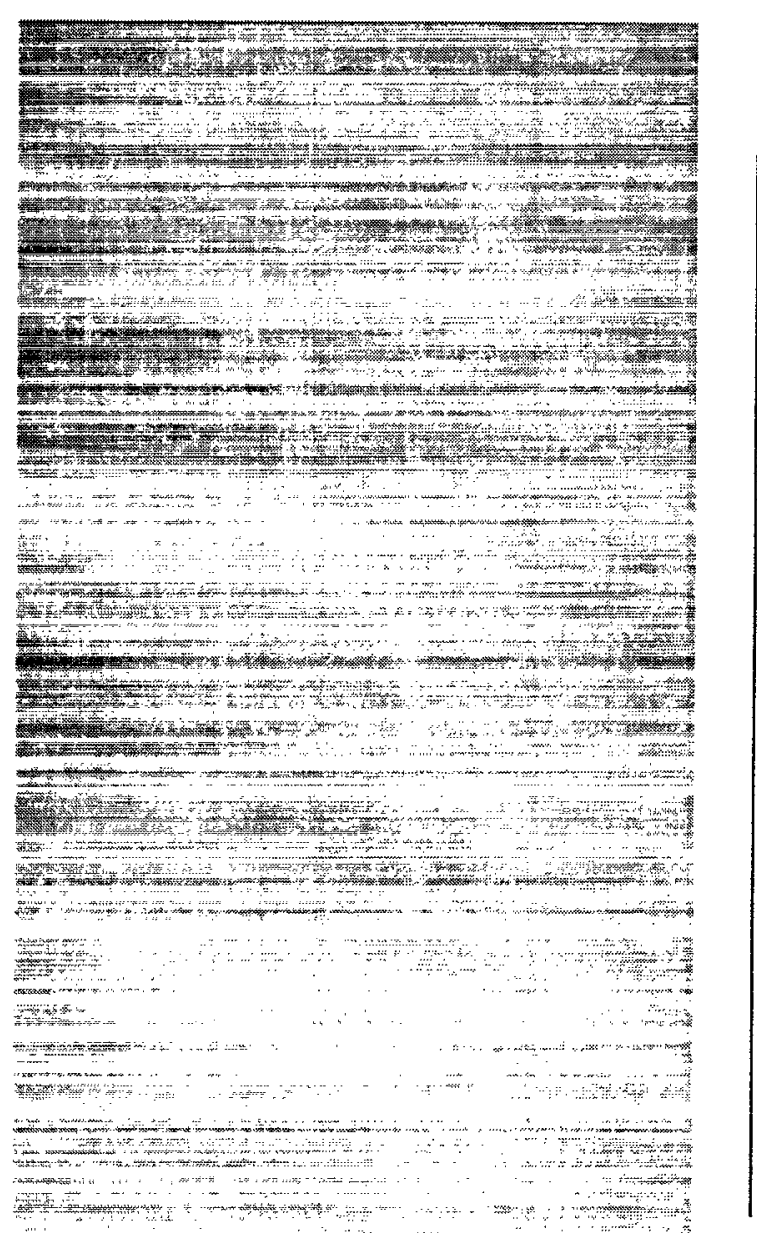

m n w w

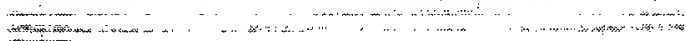
101040 and

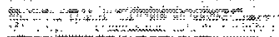

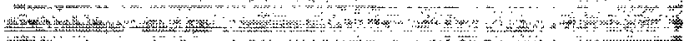

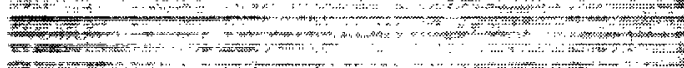
T.7.7.

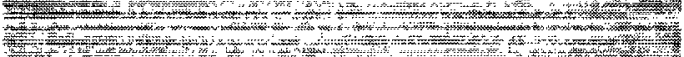

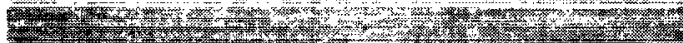
16. v-

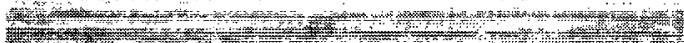

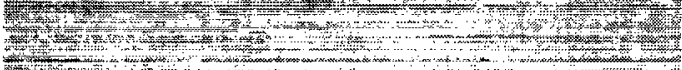
$\frac{m-1}{4+1}$

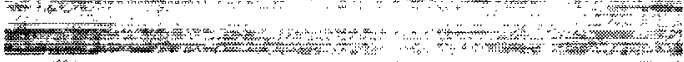

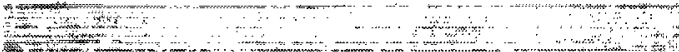

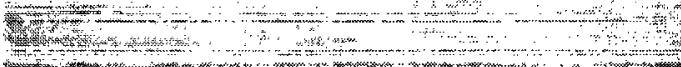

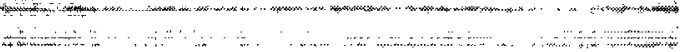

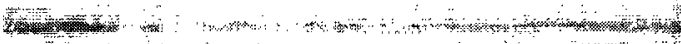

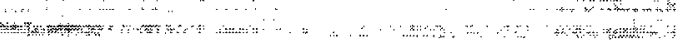

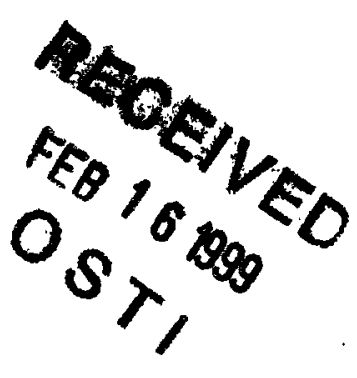

Interactions of Plutonium Dioxide with Water and Oxygen-Hydrogen Mixtures

\section{Los Alamos}

\section{WATIOALL LABOBATOS}

Los Alamos National Laboratory is operated by the University of California for the United States Department of Energy under contract W-7405-ENG-36. 
An Affirmative Action/Equal Opportunity Employer

This report was prepared as an account of work sponsored by an agency of the United States Government. Neither The Regents of the University of California, the United States

Government nor any agency thereof, nor any of their employees, makes any warranty, express or implied, or assumes any legal liability or responsibility for the accuracy, completeness, or usefulness of any information, apparatus, product, or process disclosed, or represents that its use would not infringe privately owned rights. Reference herein to any specific commercial product, process, or service by trade name, trademark, manufacturer, or otherwise, does not necessarily constitute or imply its endorsement, recommendation, or favoring by The Regents of the University of California, the United States Government, or any agency thereof. The views and opinions of authors expressed herein do not necessarily state or reflect those of The Regents of the University of California, the United States Government, or any agency thereof. Los Alamos National Laboratory strongly supports academic freedom and a researcher's right to publish; as an institution, however, the Laboratory does not endorse the viewpoint of a publication or guarantee its technical correctness. 


\section{DISCLAIMER}

Portions of this document may be illegible in electronic image products. Images are produced from the best available original document. 
Interactions of Plutonium Dioxide with Water and Oxygen-Hydrogen Mixtures

John M. Haschke*

Thomas H. Allen 


\title{
Interactions of Plutonium Dioxide with Water and Oxygen-Hydrogen Mixtures
}

\author{
by
}

John M. Haschke and Thomas H. Allen

\begin{abstract}
Pressure-volume-temperature data and mass spectrometric results obtained during exposure of $\mathrm{PuO}_{2}$ to $\mathrm{D}_{2} \mathrm{O}$ show that the dioxide reacts with water at room temperature to produce a higher oxide $\left(\mathrm{PuO}_{2+\times}\right)$ and $\mathrm{H}_{2}$. Results demonstrate that $\mathrm{PuO}_{2+x}$ is the thermodynamically stable oxide in air. The absence of $\mathrm{O}_{2}$ at detectable levels in the gas phase implies that radiolytic decomposition of water to the elements is not a significant reaction. The rate of the $\mathrm{PuO}_{2}+\mathrm{H}_{2} \mathrm{O}$ reaction is $6 \pm 4 \mathrm{nmol} \mathrm{H}_{2} / \mathrm{m}^{2}$ day, a value that is independent of the $\mathrm{H}_{2} \mathrm{O}$ concentration on the oxide over a range that extends from fractional monolayer coverage to saturation by liquid water. Evaluation of literature data shows that oxide compositions in excess of $\mathrm{PuO}_{2.25}$ are attained, but the maximum value of $\mathrm{x}$ is unknown. During exposure of $\mathrm{PuO}_{2}$ to a 2:1 $\mathrm{D}_{2}: \mathrm{O}_{2}$ mixture at room temperature, the elements combine by a process consistent with a surface-catalyzed reaction. Water is simultaneously formed by the $\mathrm{H}_{2}+\mathrm{O}_{2}$ reaction and consumed by the $\mathrm{PuO}_{2}+\mathrm{H}_{2} \mathrm{O}$ reaction and accumulates until the opposing rates are equal. Thereafter, $\mathrm{PuO}_{2+\mathrm{x}}$ is formed at a constant rate by the water-catalyzed $\mathrm{PuO}_{2}+\mathrm{O}_{2}$ reaction. The failure of earlier attempts to prepare higher oxides of plutonium is discussed and the catalytic cycle that promotes the reaction of $\mathrm{PuO}_{2}$ with $\mathrm{O}_{2}$ is described. Implications of the results for extended storage and environmental chemistry of oxide are examined. Moisturecatalyzed oxidation of $\mathrm{PuO}_{2}$ accounts for observation of both pressure increases and decreases in oxide storage containers with air atmospheres. Application of the experimental rate results indicates that the reaction of a typical oxide with 0.5 mass $\%$ of adsorbed water may be complete after 25 to 50 years at room temperature.
\end{abstract}

\section{Introduction}

Safe extended storage of surplus weapons-grade plutonium in metallic or oxide forms is necessary until disposal methods are defined and implemented. As outlined in a technical assessment of storage issues [1] and a recent review of the topic [2], dispersal of nuclear material is likely if the storage vessel is ruptured by generation of internal pressure. Expansion of the solid during corrosion of metal in unsealed containers and formation of noncondensable gases by thermal and radiolytic reactions in sealed containers are known to cause failure. Adequate understanding of the chemistry and kinetics of such processes is essential for assessing potential hazards and establishing storage criteria for plutonium.

Experimental efforts have been directed at characterizing processes that corrode plutonium or generate gases. For example, the hydride-catalyzed corrosion of metal by air 
has recently been described [3]. This process increases the corrosion rate of unalloyed plutonium by a factor of $10^{10}$ and accounts for rapid failures of storage vessels containing metal castings. Studies have also examined the behavior of adsorbates on plutonium dioxide. Water is of particular interest because it tenaciously adsorbs on the oxide and accelerates the corrosion of metal. Although water is removed by calcining, moisture readsorbs when fired oxide is exposed to air $[2,4]$. The consequences of storing $\mathrm{PuO}_{2}$ with residual moisture remain uncertain because the chemistry and kinetics of its interaction with oxide are not known.

Two potential processes by which residual water may cause excessive pressurization of oxide-containing vessels during extended storage are identified [5]. Radiolytic dissociation of water by alpha particles may produce a mixture of hydrogen and oxygen.

$$
\mathrm{H}_{2} \mathrm{O} \text { (g or adsorbed, } \alpha \text {-particle) }-->\mathrm{H}_{2}(\mathrm{~g})+1 / 2 \mathrm{O}_{2}(\mathrm{~g}) \text {. }
$$

Equation (1) is similar to the well-known radiolytic reactions of organic compounds to form polymerized products plus hydrogen and other gases $[2,6]$. Alternatively, chemical reaction of adsorbed water may form a high-stoichiometry oxide and hydrogen.

$$
\mathrm{PuO}_{2}(\mathrm{~s})+\mathrm{x} \mathrm{H}_{2} \mathrm{O} \text { (adsorbed) --> } \mathrm{PuO}_{2+\mathrm{x}}(\mathrm{s})+\mathrm{x} \mathrm{H}_{2}(\mathrm{~g}) \text {. }
$$

Occurrence of this reaction is suggested by results of $x$-ray diffraction (XRD) and $x$-ray photoelectron spectroscopy (XPS) measurements showing that the outer layer of oxide formed on the plutonium surface during reaction of the metal with water vapor at 15 torr pressure and $250^{\circ} \mathrm{C}$ is a distinct crystallographic phase containing $\mathrm{Pu}(\mathrm{VI})$ and having a value of $x$ near 0.17 [7]. Chemical and kinetic information is needed for evaluating possible risks associated with storage of oxide and for establishing the surveillance frequency of oxide containers in storage.

The present study was initiated in an effort to determine the chemical fate of residual water on weapons-grade plutonium oxide during extended storage at room temperature and to define the rate at which non-condensable gases form. If the rate of gas generation is so slow that significant pressures cannot be generated in storage containers over a period of 50-100 years, criteria for preparing oxide prior to long-term storage might be relaxed [8].

An experimental approach that involved exposure of plutonium oxide to reactants at extreme chemical conditions was adopted in an attempt to rapidly obtain relevant information.

\section{Experimental Methods}

Chemical and kinetic behavior of the gas-oxide systems at room temperature were investigated using pressure-volume-temperature (PVT) methods. During these tests, $\mathrm{PuO}_{2}$ 
was exposed to water vapor and to a 2:1 molar mixture of hydrogen and oxygen. Gas pressures and temperatures were measured continuously as a function of time $(t)$. The chemical composition of the gas phase was determined periodically by mass spectrometry (MS).

$\mathrm{PuO}_{2}$ was prepared by oxidizing weapons-grade gallium alloy in a volume-calibrated stainless steel system designed for high pressure and high vacuum applications. Metal specimens $(10.2 \mathrm{~g})$ contained in oxide-coated stainless steel crucibles were transformed into powder by repeatedly hydriding at room temperature and dehydriding at $450-500^{\circ} \mathrm{C}$ in dynamic vacuum [9]. These products were then oxidized at $500^{\circ} \mathrm{C}$ in $\mathrm{O}_{2}$. After PVT data showed that the oxidation reactions were incomplete, products were ground in an inert atmosphere glovebox and subsequently oxidized to $\mathrm{PuO}_{2.00}$ by heating in excess oxygen. The oxide products were heated at $700^{\circ} \mathrm{C}$ in dynamic vacuum to reduce residual moisture and cooled slowly to room temperature in 1.0 atm $\mathrm{O}_{2}$ to obtain a stoichiometric dioxide composition. Crucibles containing oxides were then transferred to stainless steel test reactors fitted with metallic seals, filter-protected valves, pressure transducers, and internal thermocouples. Free volumes $\left(40.0 \pm 0.1 \mathrm{~cm}^{3}\right)$ of the loaded reactors were determined by PVT methods. Adsorption of moisture by the oxide specimens during transfer in air was minimized by using protective barriers and limiting exposure times [4].

The reaction of oxide with water was investigated by exposing $\mathrm{PuO}_{2}$ to the vapor at $24.5 \pm 0.8^{\circ} \mathrm{C}$. After volume calibration, one test reactor was attached to a gas-handling manifold, evacuated, and repeatedly exposed to $\mathrm{D}_{2} \mathrm{O}$ ( $98 \%$ enrichment) vapor. Several exposures were required to saturate the oxide at an initial $\mathrm{H}_{2} \mathrm{O}$ over-pressure of 16.8 torr. The total pressure and gas-phase temperature of the test vessel were continuously monitored as a function of time with a digital data acquisition system. Gas samples were periodically taken for MS analysis. The vapor pressures of noncondendable gases were verified by measuring the residual pressure after water was frozen by cooling the bottom of the reactor with dry ice.

Interaction of oxide with possible products of water radiolysis was investigated by exposing $\mathrm{PuO}_{2}$ to a 2:1 molar mixture of $\mathrm{D}_{2}$ and $\mathrm{O}_{2}$. A limited quantity of the gas mixture was prepared by a two-step pressurization of a small stainless steel gas reservoir with $\mathrm{O}_{2}$ (99.99\%) and $\mathrm{D}_{2}(99.9 \%)$ at a 2:1 ratio using a gas manifold system. A second test reactor was evacuated and backfilled with this mixture to an initial pressure of 126.7 torr. The atmosphere in this test reactor was also monitored by continuous measurement of pressure and temperature and by periodic sampling for MS analysis. The residual gas mixture was stored in the reservoir for use as an analytical reference sample. 
Mass spectrometric data were obtained with a quadrapole instrument using gas aliquots from the test reactors. Sample volumes $\left(0.37 \mathrm{~cm}^{3}\right)$ were sufficiently small so that neither the chemical process nor the pressure measurements were disrupted. Spectra were corrected for fragmentation and ionization cross section.

Kinetic results were derived from $\mathrm{P}-\mathrm{t}$ and MS data. Reaction rates are based on pressure changes measured during corresponding time periods with the assumption of ideal gas behavior. Rates are reported in units of moles per gram or square meter of oxide per day. Rates of gas-solid reactions are strongly dependent on the specific surface area of the solid phase, but surface areas are not known and cannot be determined until the PVT experiments are terminated. However, a value of $4 \pm 3 \mathrm{~m}^{2} / \mathrm{g}$ is estimated for the oxide specimens using the correlation of the specific surface area of $\mathrm{PuO}_{2}$ with the oxide source and firing temperature [4]. Oxide specimens used in this study are assumed to have identical specific areas equal to the estimated value, but their areas could easily differ by a factor of two.

\section{Results and Discussion}

The use of test conditions selected for this study permits rapid definition the chemistry and kinetics of the interaction between plutonium dioxide and water. Radiolysis of water according to Equation 1 and chemical reaction of water according to Equation 2 should both be enhanced by a high water concentration on the oxide surface. At the initial $\mathrm{D}_{2} \mathrm{O}$ pressure ( $70 \%$ relative humidity), the anticipated surface concentration of water is about $0.6 \mathrm{mg} / \mathrm{m}^{2}$, corresponding to the presence of two layers of chemisorbed hydroxide and approximately two layers of physisorbed molecular water on the oxide surface $[4,10]$. Radiolysis of water is expected to increase the total pressure in the system by forming hydrogen and oxygen in a 2:1 ratio. A pressure increase is also anticipated for the formation of $\mathrm{PuO}_{2+\mathrm{x}}$, but in that case, analysis of the gas phase shows that hydrogen is the only gaseous product. If radiolysis and chemical reaction occur concurrently, both hydrogen and oxygen are observed, but the $\mathrm{D}_{2}: \mathrm{O}_{2}$ ratio is greater than 2 and defines the relative rates of the two reactions.

The test with a $\mathrm{D}_{2}-\mathrm{O}_{2}$ mixture provides important information about the net rate of radiolysis. If radiolytic decomposition of water is a significant process, attainment of excessively high pressures may be prevented by the recombination of hydrogen and oxygen. Formation of water is thermodynamically favored and is expected to increase with increasing temperature and pressure. A steady-state condition may exist in which the recombination rate equals the radiolysis rate. On the other hand, excessively high 
pressures are possible if the hydrogen-oxygen mixture is kinetically stable and radiolysis is sufficiently rapid.

$\mathrm{D}_{2} \mathrm{O}$ and $\mathrm{D}_{2}$ were used as reactants instead of $\mathrm{H}_{2} \mathrm{O}$ and $\mathrm{H}_{2}$ in an effort to determine if significant sources of mobile hydrogen are present in a sealed stainless steel container with oxide fired at $700^{\circ} \mathrm{C}$. The fraction of $\mathrm{H}$ increased in both test vessels over time, but evaluation of those data is incomplete. Issuance of this report describing results on the interactions of plutonium dioxide with water and with hydrogen-oxygen mixtures is needed to document the chemistry and kinetics of these systems and provide a technical basis for further work. Since the isotopic exchange of hydrogen is not evaluated, a sharp distinction between $\mathrm{D}$ and $\mathrm{H}$ is not rigorously maintained in the report, except in the evaluation of mass spectrometric data.

\section{Interaction of Plutonium Dioxide with Water}

Exposure of plutonium dioxide to water at room temperature results in formation of noncondensable gas at a measurable rate. As shown by Figure 1, the observed change in pressure during the first 100 days of the test is a linear function of time. This rate continues to be observed after almost four years.

Analytical data show that hydrogen is the only gaseous product formed during exposure of the dioxide to water. Mass spectrometric analysis of samples taken after 24 days and 72 days show that $\mathrm{D}_{2}$ and $\mathrm{D}_{2} \mathrm{O}$ are the only gases present. Absence of the $\mathrm{O}_{2}{ }^{+}$ parent peak indicates that oxygen is not present at a detectable $(0.001 \%)$ concentration. Evaluation of data for the $\mathrm{O}^{+}$peak confirms this result, but a small uncertainty remains because of possible errors in the correction for fragmentation of $\mathrm{D}_{2} \mathrm{O}$. The absence of $\mathrm{O}_{2}$ is verified by MS results for a gas sample taken while water was frozen. Measurement of the residual pressure confirms a pressure increase of 4.5 torr after 72 days and analysis of the gas sample shows that the product gas is pure hydrogen. The appearance of hydrogen and the absence of oxygen are consistent with oxidation of plutonium dioxide to $\mathrm{PuO}_{2+\mathrm{x}}$ according to Equation (2). Evidence for radiolysis of water to hydrogen and oxygen is not found. As defined by the slope of Figure 1 , the reaction rate is $12.0 \mathrm{nmol} \mathrm{H}_{2} / \mathrm{g} \mathrm{PuO}_{2}$ day at $24.5^{\circ} \mathrm{C}$. If the specific surface area of the oxide is assumed to be $4.0 \mathrm{~m}^{2} / \mathrm{g}$, this rate is equivalent to $3.0 \mathrm{nmol} \mathrm{H}_{2} / \mathrm{m}^{2}$ day.

The results of this experiment contradict the established tenet that binary plutonium oxides with compositions greater then $\mathrm{PuO}_{2}$ are unstable and cannot be prepared. This position is based on thermodynamic estimates by Brewer, who concluded that no oxides higher than $\mathrm{PuO}_{2}$ will be found in the plutonium system [11]. That conclusion is supported by failure of extensive efforts of early workers to prepare higher oxides by reacting dioxide with high-pressure $\mathrm{O}_{2}$ and strong oxidants such as atomic oxygen, $\mathrm{O}_{3}$, and $\mathrm{NO}_{2}$ [12]. 
Although early gravimetric studies indicated the formation of $\mathrm{PuO}_{2.1}$ during oxidation of the metal in air, that report is discounted and the excess mass increase is attributed to adsorption of water on the oxide [13].

The unique aspect of the present study is the direct observation of hydrogen during exposure of $\mathrm{PuO}_{2}$ to $\mathrm{H}_{2} \mathrm{O}$. Hydrogen can be produced only if plutonium is oxidized to a higher oxidation state. This conclusion is supported by XPS results showing that a binary oxide containing $\mathrm{Pu}$ (VI) is formed at the gas-oxide interface during corrosion of metal by water [7], but the calculated composition change of the oxide ( $x=0.003$ after $3.9 y)$ in our study is too small to exclude other possibilities. Although the oxide used in our tests was cooled in an $\mathrm{O}_{2}$ atmosphere to produce stoichiometric dioxide after firing, formation of a slightly substoichiometric phase $\left(\mathrm{PuO}_{2-\mathrm{x}}\right)$ with $\mathrm{x}$ less than 0.01 cannot be excluded. If so, the observed formation of hydrogen may result from oxidation of $\mathrm{Pu}(\mathrm{III})$ to $\mathrm{Pu}(\mathrm{IV})$, not from oxidation of $\mathrm{Pu}(\mathrm{IV})$ to $\mathrm{Pu}(\mathrm{VI})$.

Uncertainties about formation of $\mathrm{PuO}_{2+\mathrm{x}}$ and $\mathrm{H}_{2}$ by the reaction of water and dioxide are eliminated by results of other studies. PVT experiments in a separate study of the $\mathrm{PuO}_{2}+\mathrm{H}_{2} \mathrm{O}$ reaction at $200-350^{\circ} \mathrm{C}$ have produced compositions up to $\mathrm{PuO}_{2.17}$ [14]. The rates of $\mathrm{H}_{2}$ formation in that experimental temperature range and the value measured at $24.5^{\circ} \mathrm{C}$ in this study define a single Arrhenius relationship with an activation energy of $9.4 \pm 0.6 \mathrm{kcal} / \mathrm{mol}$. Those results and XRD data from the study are summarized in an overview of plutonium corrosion chemistry [15], but a detailed description of the work is not published. Confirmation of Equation (2) is also provided by previously unexplained results from a PVT study of plutonium corrosion in aqueous salt solution at $25^{\circ} \mathrm{C}[16,17]$. Hydrogen was generated at progressively slower rates as a sequence of reactions produced oxide hydrides of $\mathrm{Pu}(\mathrm{III}), \mathrm{Pu}_{2} \mathrm{O}_{3}$, mixed-valence oxides containing $\mathrm{Pu}(\mathrm{III})$ and $\mathrm{Pu}(\mathrm{IV})$, and $\mathrm{PuO}_{2}$. Contrary to expectation, $\mathrm{H}_{2}$ generation continued at a constant rate beyond the point at which the $\mathrm{PuO}_{2}$ stoichiometry was reached. Such behavior could not be explained and the experiment was arbitrarily terminated when the oxide composition was at $\mathrm{PuO}_{2.265^{\circ}}$. The maximum possible oxide stoichiometry in the plutonium-oxygen system at room temperature was not determined, but high-composition oxides are definitely stable.

Kinetic data from the corrosion study show that the room temperature rate of the $\mathrm{PuO}_{2}+\mathrm{H}_{2} \mathrm{O}$ reaction is the same in the liquid and vapor-phase water and imply that $\mathrm{PuO}_{2+\mathrm{x}}$ is formed in the present study. The corrosion product formed in aqueous media is an extremely fine powder and XRD data give an average particle size of about $70 \AA$ [16]. If particles are assumed to be spherical and to have a true surface area that is about 20 times larger than the geometric area, the specific surface area of the oxide is on the order of 
$750 \mathrm{~m}^{2} / \mathrm{g}$. The linear $\mathrm{H}_{2}$ generation rate reported for compositions beyond $\mathrm{PuO}_{2}$ is $2.1 \mathrm{mmol} \mathrm{H}_{2} / \mathrm{mol} \mathrm{Pu}$ day, a value equivalent to $7.80 \mu \mathrm{mol} \mathrm{H}_{2} / \mathrm{g} \mathrm{PuO}_{2}$ day. This result and the estimated specific surface area yield a rate of $10 \mathrm{nmol} \mathrm{H}_{2} / \mathrm{m}^{2}$ day that is in close agreement with the value of $3.0 \mathrm{nmol} \mathrm{H} / \mathrm{m}^{2}$ day obtained for water vapor in this study. Such agreement seems most unlikely if the reaction rate measured in our study is for oxidation of $\mathrm{PuO}_{2-\mathrm{x}}$ to $\mathrm{PuO}_{2}$.

Crystallographic data for $\mathrm{PuO}_{2.265}$ are consistent with accommodation of excess oxygen in the fluorite lattice of $\mathrm{PuO}_{2}$. XRD data for $\mathrm{PuO}_{2+\mathrm{x}}$ products prepared at elevated temperatures show a fluorite-related face-centered cubic phase with lattice parameters near the $5.397 \AA$ value of the dioxide [15]. The correlation of lattice parameter with oxide composition over the $0.016<x<0.169$ range shows that $a_{0}$ is surprisingly insensitive to $x$ with an increase of only $0.0018 \AA$ per 0.10 change in $\mathrm{x}$. The lattice parameter of fluoriterelated $\mathrm{PuO}_{2.265}(5.404 \AA)$ lies on the extrapolation of this graph to higher compositions. Excess oxygen is undoubtedly accommodated as oxide ions on vacant octahedral sites of the $\mathrm{PuO}_{2}$ lattice. Charge balance is maintained by equivalent substitution of $\mathrm{Pu}(\mathrm{VI})$ for $\mathrm{Pu}(\mathrm{IV})$ on cationic sites. Whereas the addition of oxygen tends to increase $\mathrm{a}_{0}$, substitution of $\mathrm{Pu}(\mathrm{VI})$ for $\mathrm{Pu}(\mathrm{IV})$ tends to shrink the lattice. These opposing effects are obviously of similar magnitude and their cancellation results in a low dependence of $\mathrm{a}_{0}$ on composition. $\mathrm{PuO}_{2+x}$ has undoubtedly been formed on many occasions, but was not recognize because the measured lattice parameter was in close agreement with that of $\mathrm{PuO}_{2}$. For example, the spalled corrosion product obtained during reaction of Pu with $\mathrm{H}_{2} \mathrm{O}$ vapor at $250^{\circ} \mathrm{C}$ had an $\mathrm{a}_{0}$ of $5.402 \AA$, a value corresponding to the lattice parameter of $\mathrm{PuO}_{2.15}[18]$.

The reaction of the dioxide with water shows that $\mathrm{PuO}_{2+\times}$, not $\mathrm{PuO}_{2}$, is the stable oxide in air and aqueous media. Early workers concluded that $\mathrm{PuO}_{2}$ is the stable phase because of failed attempts to oxidize $\mathrm{PuO}_{2}$ with strong oxidants that increased the free energy of reaction. These efforts to prepare higher oxides were unsuccessful because the kinetics of reaction are slow, not because the thermodynamics are unfavorable. In addition, any reaction that might have occurred was not detected by XRD because the lattice parameter is very insensitive to composition. Results of experiments conducted in the presence of moisture were rejected because observed mass increases could be attributed to adsorption of water on the oxide. Although the $\mathrm{Pu}+\mathrm{H}_{2} \mathrm{O}$ reaction is thermodynamically less favorable than many other reactions, water clearly alters the oxidation mechanism and catalyzes the oxidation of $\mathrm{PuO}_{2}$ by $\mathrm{O}_{2}$ [15].

\section{Interaction of Plutonium Dioxide with a Mixture of Hydrogen and Oxygen}

Mixtures of hydrogen and oxygen are not stable in the presence of plutonium dioxide at room temperature. Formation of water is a thermodynamically favorable reaction. 


$$
\mathrm{H}_{2}(\mathrm{~g})+1 / 2 \mathrm{O}_{2}(\mathrm{~g})-->\mathrm{H}_{2} \mathrm{O}(\mathrm{g}) \text {. }
$$

As shown by the P-t data in Figure 2, Equation (3) is not prevented by slow kinetics at the conditions of our test. The pressure drops at a rather rapid rate initially, decreases at a progressively slower rate over time, and ultimately approaches a constant rate of decrease. Kinetic results in Table 1 show that the rate slows by a factor of eighty during the first 130 days and indicate a strongly dependence of the rate on pressure.

The parametric dependencies of the reaction rate are defined by a general expression that includes temperature and the pressures of the gaseous reactants.

$$
\mathrm{R}=\operatorname{kexp}\left(-\mathrm{E}_{2} / \mathrm{R}^{*} \mathrm{~T}\right)\left(\mathrm{PO}_{2}\right)^{\mathrm{u}}\left(\mathrm{PH}_{2}\right)^{\mathrm{v}} .
$$

The reaction rate $(R)$ is a function of a proportionality constant $(k)$, temperature, oxygen pressure $\left(\mathrm{PO}_{2}\right)$, and hydrogen pressure $\left(\mathrm{PH}_{2}\right)$. The temperature dependence is described by the exponential Arrhenius term, which includes the activation energy $\left(E_{2}\right)$ and gas constant $\left(\mathrm{R}^{*}\right)$. The exponents $u$ and $v$ define the dependencies of $\mathrm{R}$ on the pressures of oxygen and hydrogen, respectively. Values of $u$ and $v$ cannot be determined from available data, but advantage is gained by fixing the gas-phase composition at the $2: 1 \mathrm{H}_{2}: \mathrm{O}_{2}$ ratio of a mixture generated by dissociation of water to the elements. Formation of water by any mixture other than 2:1 results in preferential depletion of one reactant and enrichment of the other as reaction proceeds, a condition that progressively changes gas-phase stoichiometry and may alter kinetic behavior. A 2:1 stoichiometry confines the system to a constantcomposition section of P-t space that is accurately defined by the total pressure of the gas mixture. At constant temperature and the stoichiometric ratio, the rate expression reduces to a function of the total pressure of the gas mixture.

$$
\mathrm{R}=\mathrm{k}^{\prime}(\mathrm{P})^{\mathrm{n}} \text {. }
$$

Equation 5 describes the pressure dependence of the recombination rate for the gas mixture formed by radiolysis of water. The value of $n$ is readily derived from experimental data by determining the slope of the $\ln R-\ln P$ curve.

Determination of the pressure dependence from the P-t data in Figure 1 requires that the chemical system be adequately defined. MS results for gas samples taken initially and after exposure periods of 24 days and 72 days are presented in Table 2 . Several observations merit comment. The $\mathrm{D}_{2}: \mathrm{O}_{2}$ ratio is 2.27 , not 2.00 , in the initial mixture and increases progressively to 2.75 after 72 days. Although $\mathrm{D}_{2} \mathrm{O}$ is undoubtedly formed as the pressure decreases, it is not seen in the mass spectrum. Progressive increases are also observed in the fractions of $\mathrm{H}_{2}, \mathrm{CO}$, and $\mathrm{CO}_{2}$ over time. Observed and calculated quantities of reactants and products in the reactor at zero time and after 72 days are presented in Table 3 .

The observed increase in hydrogen to oxygen ratio of the gas mixture is attributed to the combined effects of stoichiometry-driven enrichment and chemical reaction. As noted in 
the preceding discussion, occurrence of any reaction involving a gas mixture causes enrichment of the mixture in all components initially present in excess of the stoichiometric ratio for reaction. In this case, the $\mathrm{D}_{2}: \mathrm{O}_{2}$ ratio measured for the initial mixture exceeded the theoretical ratio by more than $13 \%$. Although an error in preparation of the mixture cannot be excluded, the ratio may have been increased by stripping of higher-molecular-weight $\mathrm{O}_{2}$ as the reactor was slowly filled with the gas mixture through a precision valve. Regardless of its origin, the high initial ratio results in hydrogen enrichment as reaction proceeds. However, as shown by data in Table 3 , the theoretical $2.41: 1$ ratio defined by the calculated amount of $\mathrm{D}_{2}+\mathrm{H}_{2}$ present after 72 days and the measured amount of $\mathrm{O}_{2}$ present does not account for the observed ratio. The measured quantity of hydrogen present at that point exceeds the theoretically anticipated amount by $19.0 \mu \mathrm{mol}$ and implies that water formed via Equation (3) is simultaneously reacting with the oxide to form hydrogen according to Equation (2).

Our conclusion that the $\mathrm{PuO}_{2}+\mathrm{H}_{2} \mathrm{O}$ reaction contributes to the increase in hydrogen to oxygen ratio of the gas mixture is supported by kinetic results. The average formation rate of hydrogen over the initial 72 days of exposure is defined by the mass of oxide and the quantity of excess hydrogen formed during that period. The rate of $23 \mathrm{nmol} \mathrm{H}_{2} / \mathrm{g} \mathrm{PuO}_{2}$ day ( $6 \mathrm{nmol} \mathrm{H}_{2} / \mathrm{m}^{2}$ day) derived from these results is in excellent agreement with the value of $12 \mathrm{nmol} \mathrm{H}_{2} / \mathrm{g} \mathrm{PuO}_{2}$ day measured during exposure of oxide to water and provides an independent measurement for the $\mathrm{PuO}_{2}+\mathrm{H}_{2} \mathrm{O}$ reaction at room temperature. The true rates of water formation by the hydrogen-oxygen mixture are faster than indicated by the PVT data and are accurately described by values in Table 1 after correction for hydrogen generation. Beyond 70 days, the corrected rate of $\mathrm{H}_{2} \mathrm{O}$ formation approaches the rate at which $\mathrm{H}_{2}$ is formed by the $\mathrm{PuO}_{2}+\mathrm{H}_{2} \mathrm{O}$ reaction. When the rates become equal, water and hydrogen are present in steady-state concentrations and the observed pressure decrease results solely from disappearance of $\mathrm{O}_{2}$.

The pressure dependence of the rate of the $\mathrm{H}_{2}+\mathrm{O}_{2}$ reaction in the presence of $\mathrm{PuO}_{2}$ is shown by the $\ln R-\ln P$ curve in Figure 3. The appearance of two well-defined linear regions suggests that a change in reaction mechanism occurs at $\ln P=4.79$, a point reached after 4.0 days and after a decrease of about 6.5 torr in pressure. Determination of the slopes of the two lines yields $n$ values of 46.7 and 5.9 in the high-pressure and lowpressure regimes, respectively. In the linear P-t region beyond 70 days, $R$ is constant, and $n$ is zero. A 47 th-order pressure dependence has no rational interpretation, and the $\ln R-\ln P$ relationship predicts that extremely large increases in reaction rate are induced by modest pressure changes. For example, the predicted reaction rate at a mixture pressure of 760 torr is greater than $10^{26} \mathrm{~mol} \mathrm{H}_{2}$ O/liter $\mathrm{s}$. This result is totally unreasonable, and even a sixth- 
order dependence cannot be easily explained. Although the measured pressure exponents accurately describe kinetic behavior of the experimental systems during our test, their general applicability in defining the pressure dependence of the combination rate of a nominal 2:1 $\mathrm{H}_{2}: \mathrm{O}_{2}$ mixture exposed to $\mathrm{PuO}_{2}$ is uncertain.

Examination of the full range of kinetic possibility is necessary in order to understand and interpret the behavior of hydrogen and oxygen in contact with plutonium oxide. Two questions arise: (1) Does the reaction occur in the gas phase or on a surface? (2) Is the reaction radiolytic or chemical? Both questions are addressed by considering the magnitude of the pressure exponent. Neither the extremely large pressure dependence observed initially, nor the sharp change in the exponent, is consistent with a gas-phase reaction. Such behavior is best explained as a pseudo pressure dependence that appears as water produced by the $\mathrm{H}_{2}+\mathrm{O}_{2}$ reaction adsorbs at catalytic sites on the $\mathrm{PuO}_{2}$ surface. The rate of combination slows with decreasing pressure as product water chemisorbs at the most active sites first and then progressively blocks the most active available sites. The abrupt change in rate is attributed to blockage of all sites in a distribution of highly active sites. A sixthorder pressure dependence is observed as subsequent reaction occurs at locations in a distribution of sites with relatively low catalytic activity. Reaction continues at these loweractivity sites during the steady-state process characterized by $n=0$. The observed change in rate with the extent of reaction may also be influenced by formation of $\mathrm{PuO}_{2+\mathrm{x}}$ at the surface.

Although the observed pressure exponents are consistent with chemical reaction of $\mathrm{H}_{2}$ and $\mathrm{O}_{2}$ at catalytic sites on the surface of plutonium oxide, radiolytic promotion of gasphase combination in the oxygen-hydrogen mixture merits examination. Water formation in $2: 1 \mathrm{H}_{2}: \mathrm{O}_{2}$ mixtures at pressures in 2 to 1000 torr range occurs by gas-phase thermal reaction below $400^{\circ} \mathrm{C}$ and by explosive reaction at temperatures above $580^{\circ} \mathrm{C}$ [19]. Radiolytic reaction of a material depends on the alpha flux and the rate of energy loss in the material. The primary mechanism for loss of energy by alpha particles $\left(\mathrm{He}^{2+}\right)$ in matter is coulombic interaction with electrons and formation of ion pairs [6]. Therefore, the rates of energy loss and radiolysis depend on material density. Since the density of a gaseous medium is proportional to $\mathrm{P}$, a change in pressure is expected to induce a proportionate change in the radiolysis rate. In the present experiment, a $30 \%$ decrease in pressure during the initial 150 days was accompanied by an 80 -fold decrease in rate. This observation is inconsistent with behavior anticipated for gas-phase radiolysis. Formation of water by dissociation and reaction of hydrogen and oxygen on the oxide surface is most consistent with behavior observed at room temperature in this study and with moisture-enhanced corrosion of plutonium at temperatures below $200^{\circ} \mathrm{C}[20]$. 
Occurrence of the surface-catalyzed combination reaction at room temperature is demonstrated by appearance of water in the $\mathrm{D}_{2}: \mathrm{O}_{2}$ mixture stored for use as an analytical reference. The presence of $\mathrm{H}_{2} \mathrm{O}$ was shown by MS analysis of a sample from the stainless steel reservoir after 24 days. The water obviously form by a non-radiolytic process. Indeed, the formation of water by reduction of the oxide surface on stainless steel by hydrogen is well known [21]. The reaction is responsible for significant background pressures of water in stainless systems during studies with hydrogen. Reaction in the storage reservoir may have occur by combination of dissociated hydrogen and oxygen on the surface, not by formation and reduction of an oxide intermediate. Application of a potassium chloride coating to reactor walls is apparently necessary to provide a surface with low catalytic activity for combination reactions and allow the gas-phase kinetics of $\mathrm{H}_{2}+\mathrm{O}_{2}$ mixtures to be measured [20].

The absence of water in the mass spectra of gas samples during exposure of plutonium dioxide to the hydrogen-oxygen mixture merits closer examination. Formation of $\mathrm{H}_{2} \mathrm{O}$ is implied by the disappearance of $\mathrm{H}_{2}$ and $\mathrm{O}_{2}$ and by its apparent reaction with $\mathrm{PuO}_{2}$ to increase the $\mathrm{H}_{2}: \mathrm{O}_{2}$ ratio. Water is not observed because it strongly adsorbs on the oxide [10]. The first and second surface layers form by dissociative chemisorption of $0.11 \mathrm{mg}$ $\mathrm{H}_{2} \mathrm{O} / \mathrm{m}^{2}$ in each step and produce a surface composition of $\mathrm{PuO}(\mathrm{OH})_{2}$. As the water pressure is increased, additional water adsorbs as successive molecular layers containing $0.22 \mathrm{mg} \mathrm{H} \mathrm{O}_{2} / \mathrm{m}^{2}$. The total amount of water ( $\left.69 \mu \mathrm{mol}\right)$ produced during the initial 150 days of the test is insufficient to complete the first chemisorbed layer. The equilibrium water pressure of the $\mathrm{PuO}(\mathrm{OH})_{2}$ product is below the mass spectrometric detection limit. Consequently, the net reaction for combination of $\mathrm{H}_{2}$ and $\mathrm{O}_{2}$ on the $\mathrm{PuO}_{2}$ surface at room temperature is more accurately described by Equation (6) than by Equation (3).

$$
\mathrm{H}_{2}(\mathrm{~g})+1 / 2 \mathrm{O}_{2}(\mathrm{~g}) \rightarrow-\mathrm{H}_{2} \mathrm{O} \text { (adsorbed) . }
$$

This formulation implies that the gaseous reactants adsorb and dissociate on the oxide surface prior to reaction, but does not specify the chemical nature of the adsorbed water.

The fractional coverage $(\Theta)$ of the surface by the initial chemisorbed hydroxide layer as a function of time during our test is readily derived from the kinetic results. The fractional coverages listed in Table 4 are based on the estimated surface area of the oxide and the quantity of water remaining in the reactor at each point in time. The amounts of water lost and formed are defined by P-t data in Figures 1 and 2, respectively. A two-fold uncertainty in the values arises from the uncertainty in the estimated specific surface area of the oxide. The coverage is determined largely by the rate of water formation at short times and by the rate of water consumption at long times. After four days, coverage of the surface by 
hydroxide is about $3 \%$, suggesting that this fraction of the oxide surface has high catalytic activity and is responsible for the rapid initial formation of water. The percent of surface coverage increases progressively until a steady-state concentration near $16 \%$ is established after 130 days. Beyond this point, the surface coverage and catalytic activity are constant, the $\mathrm{H}_{2}$ pressure is stable, and the rates of water formation by Equation (3) and consumption by Equation (2) are equal, but the pressure continues to decrease at a constant rate.

The continuing pressure decrease results from the water-catalyzed of $\mathrm{PuO}_{2}$ by $\mathrm{O}_{2}$. Water produced by reaction of $\mathrm{H}_{2}+\mathrm{O}_{2}$ mixture promotes the $\mathrm{PuO}_{2}+\mathrm{O}_{2}$ reaction according to the net process obtained by summing Equations (6) and (2).

$$
\begin{gathered}
\mathrm{x} \mathrm{H}_{2}(\mathrm{~g})+\mathrm{x} / 2 \mathrm{O}_{2}(\mathrm{~g}) \rightarrow \mathrm{x} \mathrm{H}_{2} \mathrm{O} \text { (adsorbed) . } \\
\mathrm{PuO}_{2}(\mathrm{~s})+\mathrm{x} \mathrm{H}_{2} \mathrm{O} \text { (adsorbed) }->\mathrm{PuO}_{2+\mathrm{x}}(\mathrm{s})+\mathrm{xH}_{2}(\mathrm{~g}) . \\
\mathrm{PuO}_{2}(\mathrm{~s})+\mathrm{x} / 2 \mathrm{O}_{2}(\mathrm{~g})->\mathrm{PuO}_{2+\mathrm{x}}(\mathrm{s}) .
\end{gathered}
$$

The direct oxidation of $\mathrm{PuO}_{2}$ by $\mathrm{O}_{2}$ is immeasurably slow, but occurs at the more rapid rate of the $\mathrm{PuO}_{2}+\mathrm{H}_{2} \mathrm{O}$ reaction when moisture is present. The linear $\mathrm{P}$-t curve observed beyond 130 days results from catalyzed reaction of oxygen according to Equation (7). Two catalytic processes work in concert. Water catalyzes the formation of higher oxide and the oxide catalyzes reaction of product hydrogen with $\mathrm{O}_{2}$.

Ingrowth of $\mathrm{H}_{2}, \mathrm{CO}$, and $\mathrm{CO}_{2}$ in the reaction mixture over time suggests the simultaneous occurrence of other chemical processes. Appearance of $\mathrm{H}_{2}$ apparently results from isotopic exchange of $\mathrm{D}_{2}$ with sources of mobile hydrogen. The most likely source is hydrogen dissolved in the stainless steel PVT reactor, but small amounts of residual hydrogen may have remained in the oxide sample after decomposition of the hydride and oxidation of the metal. The identity and extent of the hydrogen source is of interest because mobile hydrogen may become involved with the chemistry of $\mathrm{PuO}_{2}$ during extended storage in stainless steel containers. Observation of $\mathrm{CO}$ and $\mathrm{CO}_{2}$ is also of interest because excessive pressures of $\mathrm{H}_{2}$ and $\mathrm{CO}_{2}$ have formed in sealed containers of unstabilized incinerator ash after a year in storage [2,22]. Appearance of both gases in high concentrations suggests a possible reaction between carbon residues and adsorbed water.

\section{Chemistry and Kinetics of the $\mathrm{PuO}_{2}+\mathrm{H}_{2} \mathrm{O}$ Reaction}

The area-normalized reaction rate of dioxide with water is expected to depend on temperature and the concentration of adsorbed $\mathrm{H}_{2} \mathrm{O}$ on the surface. Effects of both parameters are required to interpret and predict behavior of stored oxide over a wide range of conditions. Arrhenius behavior is defined in a separate study [14] and the PVT measurement described in this report is for a single water pressure corresponding to an $\mathrm{H}_{2} \mathrm{O}$ concentration of approximately $0.6 \mathrm{mg} / \mathrm{m}^{2}$. However, evaluation of data has yielded the reaction rate at three markedly different concentrations listed in Table 5 . As defined by 
the rate of $\mathrm{H}_{2}$ formation, the rate for oxidation of plutonium dioxide by water at $25^{\circ} \mathrm{C}$ is constant at $6 \pm 4 \mathrm{~mol} \mathrm{H}_{2} \mathrm{O} / \mathrm{m}^{2}$ day even though the surface concentration of water varies by more than a 100 fold.

Independence of the $\mathrm{Pu}+\mathrm{H}_{2} \mathrm{O}$ reaction rate on the surface concentration of water appears inconsistent with the corrosion behavior of plutonium and uranium in water vapor and humid air $[19,23]$. These metals oxidize at slow, but measurable rates in dry air at room temperature. If moisture is present, the rates of oxidation increase by more than a 100 fold at room temperature. Behavior in moist air or oxygen is especially perplexing because $\mathrm{O}_{2}$, not $\mathrm{H}_{2} \mathrm{O}$, disappears from the gas phase during corrosion and $\mathrm{H}_{2}$ is not observed as a gaseous product. This behavior is demonstrated in Figure 4 by data for reaction of uranium with moist oxygen at $100^{\circ} \mathrm{C}$ [24]. Oxygen is consumed at a constant rate characteristic of humid conditions while the amount of $\mathrm{H}_{2} \mathrm{O}$ remains constant and only a trace of $\mathrm{H}_{2}$ appears. After $\mathrm{O}_{2}$ is depleted, the reaction of water ensues with production of hydrogen. The driving force for the enhanced corrosion rates of uranium and plutonium in humid conditions is the formation of higher oxides at the outer surfaces of the oxide layers on the metal $[7,15]$. The presence of the higher oxide apparently accelerates the corrosion rate by increasing the gradient in oxygen concentration across the dioxide diffusion barrier on the metal. Kinetic results for the oxidation of both metals show square-root dependencies on the vapor pressure of water[19,23]. Identical reactions occur at the gassolid interfaces during oxidation of both the metals and the dioxides. Therefore, a squareroot pressure dependence is expected for the reaction of dioxide with water.

The absence of a kinetic dependence on the $\mathrm{H}_{2} \mathrm{O}$ pressure during reaction of the dioxide with water is attributed to the absolute rate of reaction. At room temperature, the rate of the $\mathrm{Pu}+\mathrm{H}_{2} \mathrm{O}$ reaction $\left(0.3 \mathrm{mmol} \mathrm{H} \mathrm{O}_{2} \mathrm{O} \mathrm{m}^{2}\right.$ day) is $5 \times 10^{4}$ faster than that $\left(6 \mathrm{nmol} \mathrm{H}_{2} \mathrm{O} / \mathrm{m}^{2}\right.$ day) for the $\mathrm{PuO}_{2}+\mathrm{H}_{2} \mathrm{O}$ reaction. In each case, the reaction rate is determined by the temperature-dependent rate of oxygen diffusion through a layer of oxide, the thickness of the oxide layer, and the gradient in oxygen concentration across the layer. Since the thickness of the oxide layer on metal and the dimensions of oxide particles are of similar magnitude, the isothermal rate is determined primarily by the concentration gradient. The difference between the oxygen concentration in $\mathrm{PuO}_{2+\mathrm{x}}$ and $\mathrm{Pu}$ metal is very large compared to the difference between values of $\mathrm{x}$ at the surface and the interior $\mathrm{a} \mathrm{PuO}_{2+\mathrm{x}}$ particle. At the slow rate of the $\mathrm{PuO}_{2}+\mathrm{H}_{2} \mathrm{O}$ reaction, ample water is available to maintain the small oxygen gradient, even when the surface coverage by water is fractional. The surface is effectively saturated at all conditions in Table 5 and the observed rate is independent of water concentration. At the comparatively rapid rate of the $\mathrm{Pu}+\mathrm{H}_{2} \mathrm{O}$ reaction, the surface concentration of water is less than the saturated condition. Therefore, the value of $\mathrm{x}$ and 
the concentration gradient are sensitive to changes in water pressure and a pressure dependence is observed. Appearance of a square-root pressure dependence for the $\mathrm{PuO}_{2}+\mathrm{H}_{2} \mathrm{O}$ reaction is anticipated at surface concentrations of water below those listed in Table 5.

Kinetic results for metal corrosion are applied in defining chemistry of the reaction between dioxide and moist air or oxygen. As defined by Equation (7), the $\mathrm{PuO}_{2}+\mathrm{O}_{2}$ reaction occurs during the constant-rate stage of the reaction with $\mathrm{H}_{2}+\mathrm{O}_{2}$ mixtures. However, during out test, important details of the reaction mechanism are masked by the presence of a large and stable quantity of deuterium in the reactor. The reaction of dioxide with moist air or oxygen is undoubtedly like that observed during moisture-enhanced corrosion of uranium and plutonium. Oxygen disappears at the rapid rate characteristic of the $\mathrm{H}_{2} \mathrm{O}$ reaction, but $\mathrm{H}_{2}$ is not formed. This behavior suggest that the catalytic cycle identified for the $\mathrm{PuO}_{2}+\mathrm{O}_{2}$ reaction in the preceding section is best described by a sequence of reactions in which product hydrogen remains on the oxide surface.

$$
\begin{aligned}
& \mathrm{PuO}_{2} \text { (s) }+x \mathrm{H}_{2} \mathrm{O} \text { (adsorbed) }->\mathrm{PuO}_{2+\mathrm{x}}+2 \mathrm{x} \mathrm{H} \text { (adsorbed) } \text {. } \\
& \mathrm{x} / 2 \mathrm{O}_{2}(\mathrm{~g})=\mathrm{xO} \text { (adsorbed) . } \\
& 2 \times \mathrm{H} \text { (adsorbed) }+\times \mathrm{O} \text { (adsorbed) }-\rightarrow \mathrm{x} \mathrm{H}_{2} \mathrm{O} \text { (adsorbed) . } \\
& \mathrm{PuO}_{2}(\mathrm{~s})+\mathrm{x} / 2 \mathrm{O}_{2}(\mathrm{~g})-->\mathrm{PuO}_{2+\mathrm{x}} \text { (s) . }
\end{aligned}
$$

Reaction of adsorbed water with $\mathrm{PuO}_{2}$ to form $\mathrm{PuO}_{2+\mathrm{x}}$ according to Equation (8) determines the rate at which higher oxide is formed. Atomic hydrogen from this reaction combines with atomic oxygen formed via Equation (9). The catalytic cycle is entered as $\mathrm{H}_{2} \mathrm{O}$ from Equation (10) reacts with $\mathrm{PuO}_{2+\mathrm{x}}$ from Equation (8) to progressively increase $\mathrm{x}$ of the higher oxide. The net reaction given by Equation 11 proceeds at the characteristic rate of the $\mathrm{PuO}_{2}+\mathrm{H}_{2} \mathrm{O}$ reaction.

The chemistry and kinetics of $\mathrm{PuO}_{2}$ oxidation by moisture are complex, but relevant to several areas of plutonium technology. Results directly address the possibility of pressurizing storage containers with $\mathrm{H}_{2}$ from the $\mathrm{PuO}_{2}+\mathrm{H}_{2} \mathrm{O}$ reaction. A relationship presented in the DOE standard for storage of high-purity metal and oxide describes the maximum $\mathrm{H}_{2}$ pressure from Equation (2) as a function of oxide mass, the loss-on-ignition (LOI) value for the oxide, the free volume in the container, and temperature [8]. At room temperature, a pressure change of 150 psi is calculated for complete reaction of 0.5 mass \% water on $3.0 \mathrm{~kg}$ of oxide in a container with 2.0 liters of free volume. The time period for reaction can now be estimated because the rate of $\mathrm{H}_{2}$ formation $\left(6 \mathrm{nmol} / \mathrm{m}^{2}\right.$ day) is constant over a concentration range that extends from saturation to LOI values below $0.01 \%$. This estimation is based on the assumption that the oxide composition, the $\mathrm{H}_{2}$ pressure, and the $\mathrm{H}_{2} \mathrm{O}$ concentration do not satisfy the equilibrium constant for Equation (2) at $25^{\circ} \mathrm{C}$ before 
all water has reacted. Complete reaction of water in the storage configuration described above is expected after 25 years if the specific surface area of the oxide is $5.0 \mathrm{~m}^{2} / \mathrm{g}$ and after 50 years if the area is $2.5 \mathrm{~m}^{2} / \mathrm{g}$. These time periods are for reaction of adsorbed moisture and cannot be directly applied to the reaction of water present as hydroxide or as water of crystallization in the solid.

Prediction of pressure behavior in a storage container is complicated by the possible involvement of other reactions. The calculated time for complete reaction of water according to Equation (2) applies only if the storage atmosphere is inert and adsorbed water is the only reactive species in the system. If oxygen is present in addition to moisture, the pressure in the storage container decreases initially as the water-catalyzed $\mathrm{PuO}_{2}+\mathrm{O}_{2}$ reaction proceeds via Equation (11). The pressure increases after $\mathrm{O}_{2}$ is depleted and $\mathrm{H}_{2}$ is formed by reaction of water according to Equation (2). Our results suggest that the water-catalyzed rate of $\mathrm{O}_{2}$ consumption during storage of $\mathrm{PuO}_{2}$ in oxygen-containing environments is invariant over a wide range of water concentration and depends only on the specific surface area of the oxide and the temperature. The rates $\mathrm{O}_{2}$ consumption in moist, oxygencontaining storage environments are expected to be equal after normalization for oxide surface area. Evaluation of pressure data from containers with air atmospheres may afford a direct and facile method for assessing chemical and kinetic results of this study and for defining the equilibrium behavior of Equation (2).

The water-catalyzed regime may be entered with air-filled storage containers even though water was initially absent. If organic materials are present, $\mathrm{H}_{2}$ produced by their radiolysis combines with $\mathrm{O}_{2}$ on the oxide surface to form water and catalyze the $\mathrm{PuO}_{2}+\mathrm{O}_{2}$ reaction.

Potential consequences of $\mathrm{PuO}_{2+\mathrm{x}}$ formation reach far beyond concerns about safe storage of oxide. The presence of $\mathrm{U}(\mathrm{VI})$ is known to increase the solubility of $\mathrm{UO}_{2+\mathrm{x}}$ in aqueous media. When heated, the higher oxide reverts to $\mathrm{PuO}_{2}$ via an auto-redox reaction that reduces $\mathrm{Pu}(\mathrm{VI})$ to $\mathrm{Pu}(\mathrm{IV})$ and releases $\mathrm{O}_{2}$ [17]. The unexplained slow dissolution rate of "high-fired" plutonium oxide is consistent with the absence of $\mathrm{Pu}(\mathrm{VI})$ in oxides calcined at elevated temperatures. $\mathrm{PuO}_{2+\mathrm{x}}$ is the stable oxide in air and its formation in natural environments is expected. Leaching of the hexavalent ion from $\mathrm{PuO}_{2+\mathrm{x}}$ is consistent with the appearance of $\mathrm{Pu}(\mathrm{V}, \mathrm{VI})$ instead of $\mathrm{Pu}(\mathrm{IV})$ in natural waters coexisting with oxide $[25,26]$. According to the established model for aqueous transport, only a small fraction $\left(<10^{-3}\right)$ of plutonium in soils is soluble and available for migration. Our observations suggests that continuous oxidation and leaching of environmental oxide is likely. 


\section{Conclusions}

This PVT and MS study demonstrates that a noncondensable gas is formed by the interaction of plutonium dioxide with adsorbed water at room temperature. Hydrogen and $\mathrm{PuO}_{2+\mathrm{x}}$ are produced by the chemical reaction of $\mathrm{PuO}_{2}$ with $\mathrm{H}_{2} \mathrm{O}$. Occurrence of a redox reaction is demonstrated by the formation of $\mathrm{H}_{2}$. Unlike results of gravimetric measurements, results of the PVT-MS measurements cannot be attributed to mass changes arising from adsorption of water by the oxide. $\mathrm{PuO}_{2+\mathrm{x}}$, not $\mathrm{PuO}_{2}$, is the stable oxide in air at room temperature. Earlier attempts to prepare higher oxides failed because of slow reaction kinetics. The reaction of dioxide with water is faster than the reactions of other oxidants and is readily monitored by the appearance of $\mathrm{H}_{2}$.

Radiolysis of water is not a credible pressurization process during storage of WR plutonium oxide. Exposure of a $2: 1 \mathrm{H}_{2}: \mathrm{O}_{2}$ mixture to $\mathrm{PuO}_{2}$ shows that water forms as predicted by thermodynamics. Kinetic data are most consistent with catalyzed association of the elements on the plutonium oxide surface. The significant result is that the combination rate of hydrogen and oxygen in the simulated oxide storage configuration of our tests greatly exceeds the radiolysis rate of water. Detailed knowledge of the combination mechanism in not required for addressing issues of safe oxide storage.

Pressurization of sealed containers by hydrogen from the $\mathrm{PuO}_{2}+\mathrm{H}_{2} \mathrm{O}$ reaction is possible if adsorbed water is present on stored oxide. The rate of $\mathrm{H}_{2}$ formation is slow, but sufficient to consume large amounts of adsorbed water during extended storage. A surprising result needing verification is the apparent independence of the reaction rate on the surface concentration of water. The absence of $\mathrm{O}_{2}$ in the gas phase shows that radiolysis of water is insignificant. The results establish the technical basis for using a modified relationship in calculating the maximum total pressure in a storage container of oxide [8]. The earlier version of the relationship over-estimates the maximum pressure increase because radiolysis of adsorbed water was assumed to produce a mixture of oxygen and hydrogen.

The chemical system is unusually complex in atmospheres containing dioxide and oxygen, along with moisture, hydrogen, or a potential source of radiolytic hydrogen. Water is simultaneously consumed by the $\mathrm{PuO}_{2}+\mathrm{H}_{2} \mathrm{O}$ reaction and formed by the $\mathrm{H}_{2}+\mathrm{O}_{2}$ reaction and the system adjusts until the opposing rates are equal. The system pressure decreases as $\mathrm{PuO}_{2+\mathrm{x}}$ is produced at a constant rate by the water-catalyzed $\mathrm{PuO}_{2}+\mathrm{O}_{2}$ reaction. After $\mathrm{O}_{2}$ is depleted, formation of $\mathrm{H}_{2}$ by the $\mathrm{PuO}_{2}+\mathrm{H}_{2} \mathrm{O}$ reaction causes the pressure to increase, and except for the possible presence of residual $\mathrm{N}_{2}$ from air, the final chemical system is indistinguishable from that achieved by exposing $\mathrm{PuO}_{2}$ to $\mathrm{H}_{2} \mathrm{O}$. Care must be 
exercised so that surveillance of storage containers does not coincide with the point at which the net pressure change is fortuitously negligible.

Important issues have been resolved by this study, but others remain. Although water present in the oxide as hydroxide or as waters of hydration is expected to react and form $\mathrm{PuO}_{2+\mathrm{x}}$ and $\mathrm{H}_{2}$, neither the thermodynamics nor the kinetics of those reactions are known. Isotopic exchange observed in our study shows that mobile hydrogen is present in stainless steel vessels containing oxide. The origin of the hydrogen and the possibility of its involvement in pressurization processes are uncertain. Results also suggest that $\mathrm{CO}$ and $\mathrm{CO}_{2}$ are formed when WR oxide is exposed to water. Investigation of such reactions is needed to characterize other potential pressurization processes and to describe the complex chemical and catalytic properties of plutonium oxide. 


\section{References}

1. "Assessment of Plutonium Storage Safety Issues at Department of Energy Facilities," Department of Energy Report DOE/DP-0123T, U.S. Department of Energy, Washington, DC, January 1994.

2. J. M. Haschke and J. C. Martz, "Plutonium Storage," in Encyclopedia of Environmental Analysis and Remediation, R. A. Meyers, ed., Vol. 6, John Wiley and Sons, Inc., New York, 1998, pp. 3740-3755.

3. J. M. Haschke, T. H. Allen, and J. C. Martz, J. Alloys Comp., 271-273 (1998) 211.

4. J. M. Haschke and T. E. Ricketts, "Plutonium Dioxide Storage: Conditions for Preparation and Handling," Los Alamos Laboratory Report LA-12999-MS, Los Alamos National Laboratory, Los Alamos NM, August 1995.

5. J. M. Haschke, "DOE Storage Criteria" in Quarterly Status Report April 1-June 30, 1995; The Nuclear Materials Packaging and Repackaging Project, Los Alamos Laboratory Report LA-UR-95-2646, Los Alamos National Laboratory, Los Alamos NM, July 1995.

6. G. Friedlander, J. W. Kennedy, and J. M. Miller, Nuclear and Radiochemistry, Second Edition, John Wiley and Sons, Inc., New York, 1964, Chap. 4.

7. J. L. Stakebake, D. T. Larson, and J. M. Haschke, J. Alloys Comp., 202 (1993) 251.

8. "Criteria for Preparing and Packaging Plutonium Metals and Oxides for Long-Term Storage," Department of Energy Standard DOE-STD-3013, U.S. Department of Energy, Washington, DC, September 1996.

9. J. M. Haschke, "Actinide Hydrides," in G. Meyer and L. R. Morse, eds., Topics in f-Element Chemistry: Synthesis of Lanthanide and Actinide Compounds, Chap. 1, Kluwer Academic Publishers, Dordrecht, Netherlands, 1991.

10. J. M. Haschke and T. E. Ricketts, J. Alloys Comp., 252 (1997) 148.

11. L. Brewer, Chem. Rev:, 52 (1953) 1.

12. J. M. Cleveland, The Chemistry of Plutonium, Chap. 9, American Nuclear Society, La Grange Park, IL, 1979.

13. J. T. Waber, "Corrosion and Oxidation," in O. J. Wick, ed., Plutonium Handbook, Chap. 6, American Nuclear Society, La Grange Park, IL, 1980.

14. L. Morales, J. Haschke, and P. Kleinschmidt, "Investigation of the Plutonium OxideWater Reaction," Final Programme and Abstracts, Actinides '97 International

Conference, Presentation T8-P23, Baden-Baden, Germany, September 21-26, 1997, Institute for Transuranium Elements, Karlsruhe, Germany, September 1997.

15. J. M. Haschke, T. H. Allen, and L. A. Morales, "Surface and Corrosion Chemistry of Plutonium," Los Alamos Laboratory Report LA-UR-98-2297, Los Alamos National Laboratory, Los Alamos NM, June 1998, to be published in Los Alamos

Science, 1999. 
16. J. M. Haschke, A. E. Hodges, G. E. Bixby, and R. L. Lucas, "The Reaction of Plutonium with Water: Kinetic and Equilibrium Behavior of Binary and Ternary Phases in the Pu+O+H System." Rocky Flats Report RFP-3416, Rockwell International, Rocky Flats Plant, Golden, CO, February 1983.

17. J. M. Haschke, "Hydrolysis of Plutonium: The Plutonium-Oxygen Phase Diagram," in L. R. Morss and J. Fuger, eds., Transuranium Elements A Half Century, American Chemical Society, Washington, DC, 1992.

18. J. L. Stakebake and M. A. Saba, J. Less-Common Metals, 158 (1990) 221.

19. B. Lewis and G. v. Elbe, Combustion, Flames and Explosions of Gases, Academic Press, New York, 1953.

20. J. M. Haschke, T. H. Allen, and J. L. Stakebake, J. Alloys Comp., 243 (1996) 23.

21. J. C. Beavis, J. Vac. Sci. Technol., 10 (1973) 386.

22. B. H. Ives, "Bulged Cans: Initial Discovery and Response," Lawrence Livermore National Laboratory, Livermore, CA, Technical Presentation at Los Alamos National Laboratory, December, 1994.

23. J. M Haschke, "Corrosion of Uranium in Air and Water Vapor: Consequences for Environmental Dispersal,"Los Alamos Laboratory Report LA-UR-98-231, Los Alamos National Laboratory, Los Alamos NM, January 1998, accepted for publication in J. Alloys Comp., 1998.

24. M. McD. Baker, L. N. Ness, and S. Orman, Trans. Faraday Soc., 62 (1966) 2525.

25. R: C. Dahlman, E. A. Bondietti, and D. Eyman, "Biological Pathways and Chemical Behavior of Plutonium and Other Actinides in the Environment," in Actinides in the Environment, A. M. Friedman, ed., Amer. Chem. Soc. Symp. Ser. No. 35, American Chemical Society, Washington, DC, 1976, pp. 47-80.

26. D. Rai, R. J. Serne, and J. L. Swanson, J. Environ. Qual., 9 (1980) 417. 
Table 1. Experimental Data and Kinetic Results for the Reaction of $\mathrm{D}_{2}+\mathrm{O}_{2}$ Mixture Exposed to $\mathrm{PuO}_{2}$ at $24^{\circ} \mathrm{C}^{\mathrm{a}}$

\begin{tabular}{|c|c|c|c|}
\hline \multirow[t]{2}{*}{$\underset{\text { (days) }}{\text { Elapsed Time }(t)}$} & \multirow[t]{2}{*}{$\begin{array}{l}\text { Total Pressure }(\mathrm{P}) \\
\text { (torr) }\end{array}$} & \multicolumn{2}{|c|}{$\underset{\left(\mu \mathrm{mol} \mathrm{H}_{2} \mathrm{O} / \mathrm{g} \mathrm{PuO}_{2} \mathrm{~d}\right)}{\operatorname{Reaction} \text { Rate }(\mathrm{R})^{\mathrm{b}}}$} \\
\hline & & Experimental & Corrected \\
\hline 0 & 126.7 & -- & -- \\
\hline 0.125 & 125.9 & 0.80 & 0.82 \\
\hline 0.250 & 125.3 & 0.60 & 0.62 \\
\hline 0.375 & 124.8 & 0.50 & 0.51 \\
\hline 0.500 & 124.4 & 0.39 & 0.40 \\
\hline 0.75 & 123.8 & 0.30 & 0.31 \\
\hline 1.0 & 123.3 & 0.25 & 0.26 \\
\hline 1.5 & 122.5 & 0.21 & 0.22 \\
\hline 2.0 & 121.8 & 0.18 & 0.19 \\
\hline 2.5 & 121.3 & 0.13 & 0.14 \\
\hline 3.0 & 120.9 & 0.10 & 0.11 \\
\hline 4.0 & 120.2 & 0.085 & 0.097 \\
\hline 5.0 & 119.6 & 0.079 & 0.091 \\
\hline 10 & 117.0 & 0.065 & 0.077 \\
\hline 15 & 114.5 & 0.064 & 0.075 \\
\hline 20 & 112.3 & 0.055 & 0.067 \\
\hline 25 & 110.3 & 0.050 & 0.062 \\
\hline 35 & 107.0 & 0.041 & 0.053 \\
\hline 45 & 104.3 & 0.038 & 0.050 \\
\hline 50 & 102.3 & $0.034^{c}$ & 0.046 \\
\hline 60 & 99.6 & $0.018^{c}$ & 0.030 \\
\hline 70 & 97.6 & $0.017^{c}$ & 0.029 \\
\hline 130 & 90.0 & $0.010^{c}$ & 0.022 \\
\hline 145 & 88.7 & $0.016^{\mathrm{c}}$ & 0.028 \\
\hline
\end{tabular}

a. The initial $\mathrm{D}_{2}: \mathrm{O}_{2}$ ratio of the mixture was $2.27: 1$.

b. Experimental rates are based on the measured $P-t$ data; corrected rates are adjusted for concurrent generation of $\mathrm{H}_{2}$ at the constant rate $\left(12.0 \mathrm{nmol} \mathrm{H} / \mathrm{g} \mathrm{PuO}_{2}\right.$ day) of the $\mathrm{PuO}_{2}+\mathrm{H}_{2} \mathrm{O}$ reaction.

c. Whereas rates at low pressures are derived from the incremental $\mathrm{P}$ and $\mathrm{t}$ changes relative to values for the preceding data point, this rate is based on P-t data measured several days before and after the indicated median time. 
Table 2. Mass Spectrometric Results for the Gas Phase after Different Time Periods during Exposure of the $\mathrm{D}_{2}+\mathrm{O}_{2}$ Reaction Mixture to $\mathrm{PuO}_{2}$ at Room Temperature

\begin{tabular}{|c|c|c|c|}
\hline \multirow[t]{2}{*}{$\begin{array}{l}\text { Gaseous } \\
\text { Constituent }\end{array}$} & \multicolumn{3}{|c|}{$\begin{array}{l}\text { Mole Percentage after Indicated } \\
\text { Exposure Period in Days }\end{array}$} \\
\hline & 0 & 24 & 72 \\
\hline $\mathrm{H}_{2}$ & 0.000 & 0.33 & 0.56 \\
\hline $\mathrm{D}_{2}$ & 69.43 & 71.80 & 71.85 \\
\hline $\mathrm{CO}$ & 0.014 & 0.14 & 0.35 \\
\hline $\mathrm{O}_{2}$ & 30.55 & 27.62 & 26.38 \\
\hline $\mathrm{CO}_{2}$ & 0.010 & 0.10 & 0.87 \\
\hline
\end{tabular}

a. The molar ratio of $\mathrm{D}_{2}: \mathrm{O}_{2}$ in the initial mixture is $2.27: 1$, a value that is approximately equal to the 2:1 ratio for gases produced by radiolytic decomposition of water. 
Table 3. Quantification of Reactants and Products during Exposure of $\mathrm{D}_{2}+\mathrm{O}_{2}$ Mixture to $\mathrm{PuO}_{2}$ at Room Temperature ${ }^{\mathrm{a}, \mathrm{b}}$

\section{Quantity}

Exposure Period in Days

0

72

a. Experimental values are based on the measured moles of gas present in the reactor and composition data in Table 2.

b. Theoretical values are based on the experimental quantities of oxygen and the stiochiometry of Equation 3.

c. $\mathrm{H}_{2}$ in the reactor is assumed to result from exchange with $\mathrm{D}_{2}$ and the molar sum of the two isotopes is used for all calculations involving hydrogen and water. 
Table 4. Time Dependence of Water Concentration on the Dioxide Surface during Exposure of a $\mathrm{D}_{2}+\mathrm{O}_{2}$ Mixture to $\mathrm{PuO}_{2}$ at Room Temperature

\begin{tabular}{cccc}
\hline $\begin{array}{c}\text { Elapsed Time } \\
(t \text { in days })\end{array}$ & \multicolumn{2}{c}{$\begin{array}{c}\text { Quantity of Water } \\
(\mu \mathrm{mol})\end{array}$} & $\begin{array}{c}\text { Fractional Coverage }^{\mathrm{b}} \\
(\Theta)\end{array}$ \\
\cline { 2 - 4 } 1 & Formed $^{\mathrm{R}}$ & \\
\hline 1 & 4.0 & 3.9 & 0.013 \\
2 & 7.2 & 6.9 & 0.024 \\
5 & 10.4 & 9.7 & 0.033 \\
10 & 14.8 & 13.4 & 0.056 \\
20 & 22.6 & 19.8 & 0.068 \\
30 & 29.4 & 25.1 & 0.086 \\
50 & 40.3 & 33.4 & 0.114 \\
70 & 48.4 & 38.7 & 0.132 \\
100 & 56.8 & 43.0 & 0.147 \\
130 & 65.1 & 47.2 & 0.161 \\
150 & 69.0 & 48.3 & 0.164 \\
\hline
\end{tabular}

a. The amount of water formed is calculated from the experimental $P-t$ data after correction of $P$ for formation of hydrogen a rate of $12.0 \mathrm{nmol} / \mathrm{g} \mathrm{PuO}_{2} \mathrm{~d}$; the amount of water present at each point in time is defined by the amount formed and the amount consumed by reaction.

b. Values of $\Theta$ are calculated using a specific surface area of $4.0 \mathrm{~m}^{2} / \mathrm{g}$ for $\mathrm{PuO}_{2}$ and a water concentration of $0.11 \mathrm{mg} \mathrm{H} \mathrm{H}_{2} \mathrm{O} / \mathrm{m}^{2}$ in the first chemisorbed hydroxide layer. 
Table 5. Kinetic Results for the $\mathrm{PuO}_{2}+\mathrm{H}_{2} \mathrm{O}$ Reaction at Room Temperature and Different Concentrations of Adsorbed Water

\begin{tabular}{cccc}
\hline $\begin{array}{c}\text { Reaction } \\
\text { Conditions }\end{array}$ & $\begin{array}{c}\mathrm{H}_{2} \mathrm{OCO}_{\text {Concentration }} \\
\text { On Oxide Surface } \\
\left(\mathrm{mg} / \mathrm{m}^{2}\right)\end{array}$ & $\begin{array}{c}\mathrm{LOI}^{\mathrm{b}} \\
(\%)\end{array}$ & $\begin{array}{c}\text { Rate of } \mathrm{H}_{2} \\
\text { Formation } \\
\left(\mathrm{nmol} \mathrm{H}_{2} / \mathrm{m}^{2} \mathrm{~d}\right)\end{array}$ \\
\hline $2: 1 \mathrm{H}_{2}: \mathrm{O}_{2}$ Mixture & 0.01 & $0.002-0.008$ & 6 \\
16.8 torr $\mathrm{H}_{2} \mathrm{O}$ Vapor & 0.6 & $0.1-0.5$ & 3 \\
Liquid Water & $>2.2$ & 3 & 10 \\
\hline
\end{tabular}

a. The surface concentration of $\mathrm{H}_{2} \mathrm{O}$ on the oxide exposed to the gas mixture is the steady-state value calculated from kinetic data; values for vapor-phase and liquid water are estimated using data in the report by Haschke and Ricketts (Reference 4).

b. LOI is percentage of mass loss on ignition at $950^{\circ} \mathrm{C}$. LOI values are based on the $\mathrm{H}_{2} \mathrm{O}$ concentration and the estimated range of specific surface areas of the oxides. The value for liquid water is based on estimated surface area and the equilibrium $\mathrm{H}_{2} \mathrm{O}$ concentration $\left(0.4 \mathrm{mg} / \mathrm{m}^{2}\right)$ in air at a relative humidity of $10 \%$ to $60 \%$ at $25^{\circ} \mathrm{C}$. 


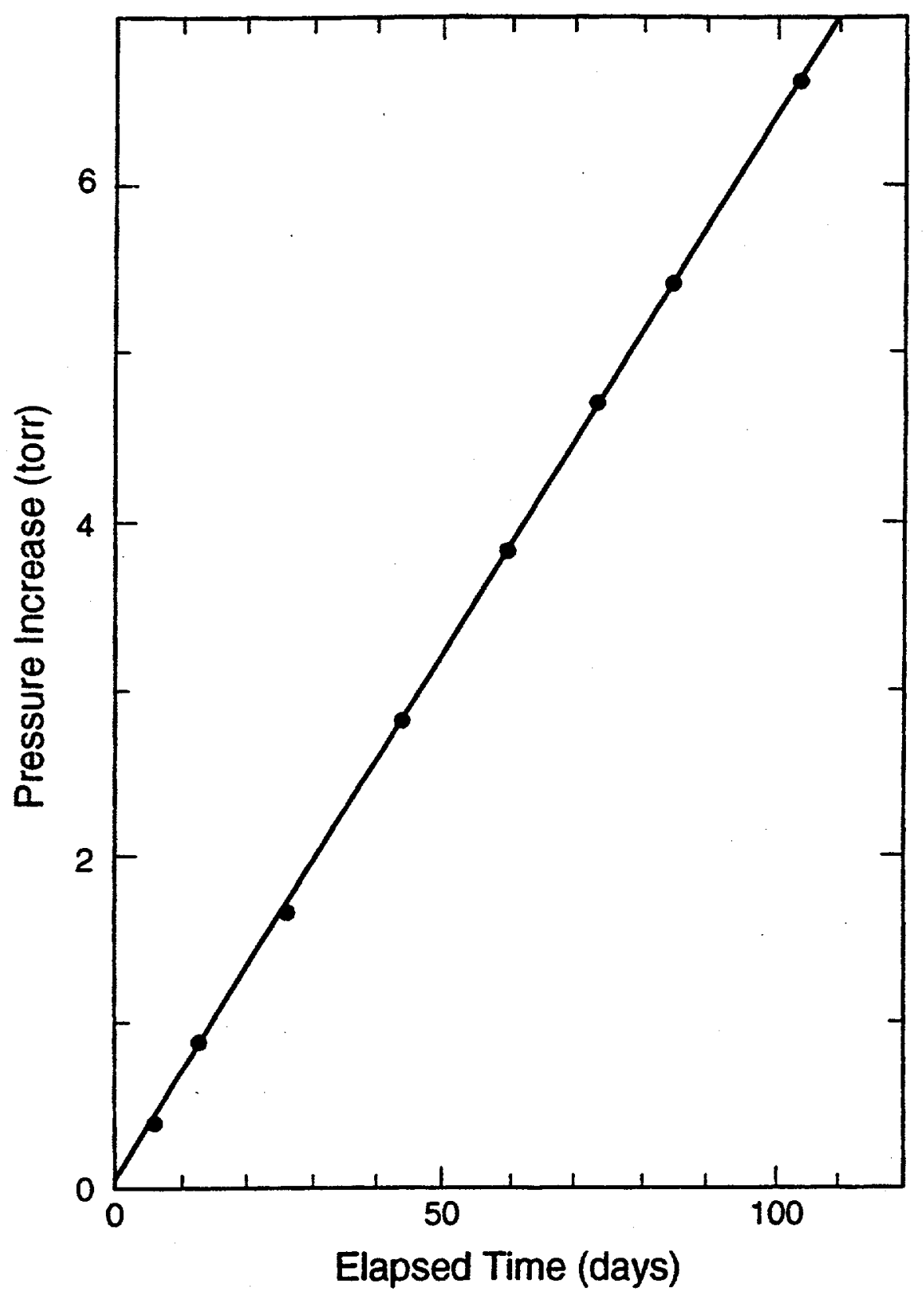

Figure 1. Time dependence of the pressure change during exposure of $\mathrm{PuO}_{2}$ to $\mathrm{D}_{2} \mathrm{O}$ at $24.5^{\circ} \mathrm{C}$ and an initial pressure of 16.8 torr. 


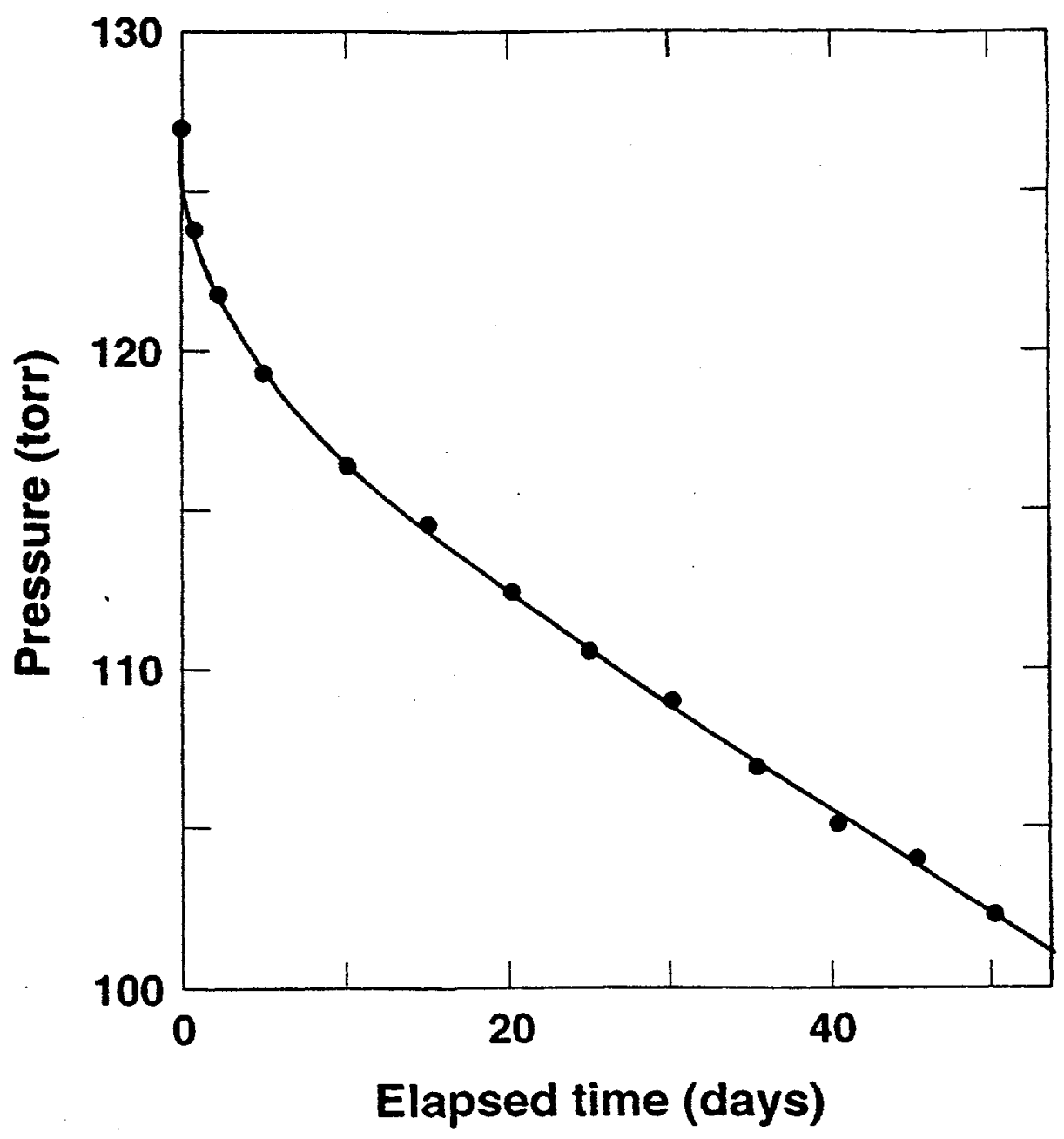

Figure 2. Time dependence of the pressure during exposure of $\mathrm{PuO}_{2}$ to a $2: 1 \mathrm{D}_{2}: \mathrm{O}_{2}$ mixture at $24.5^{\circ} \mathrm{C}$ and an initial pressure of 126.7 torr. 


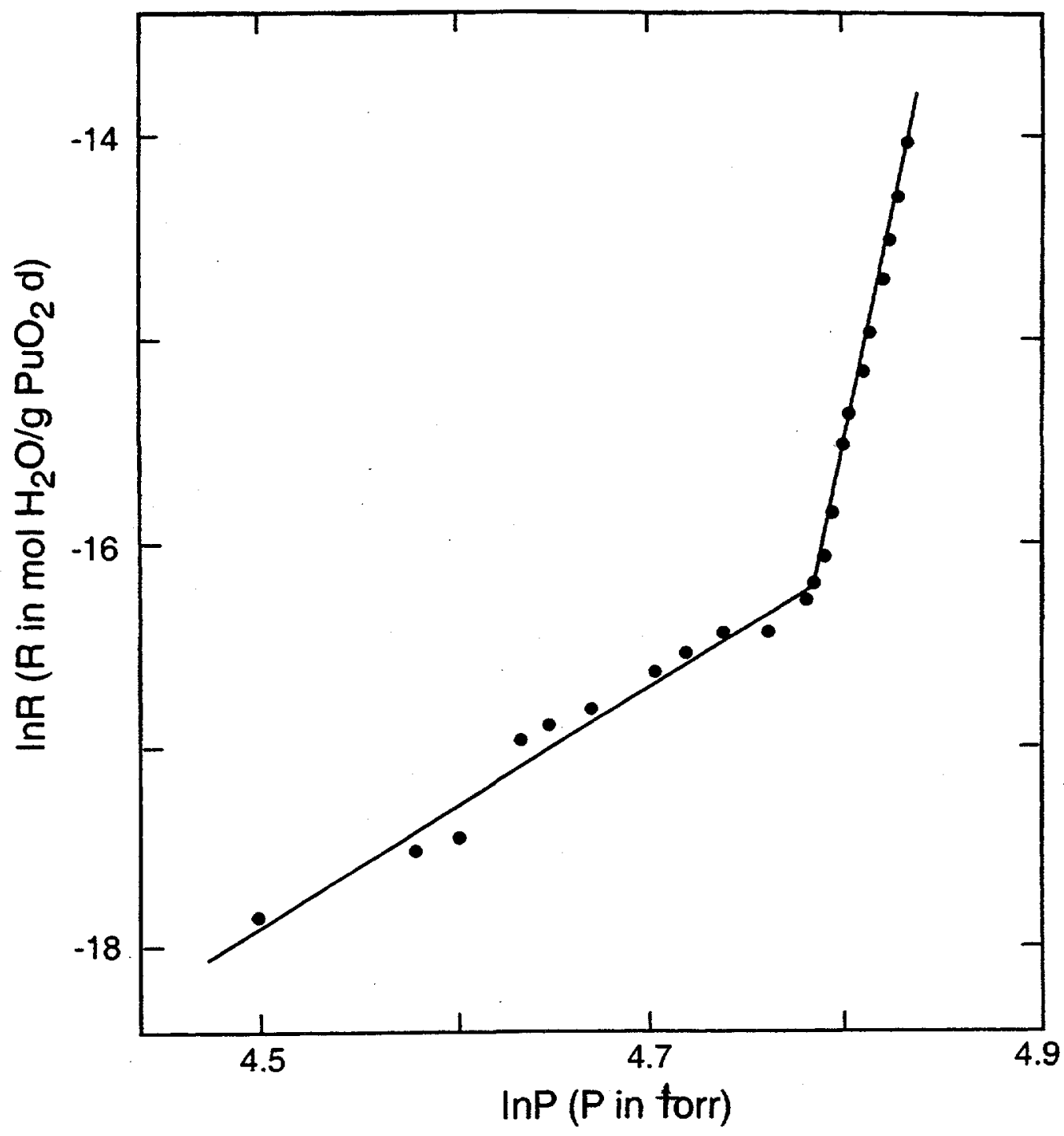

Figure 3. Dependence of $\operatorname{lnR}$ on $\ln \mathrm{P}$ for the $\mathrm{H}_{2}+\mathrm{O}_{2}$ reaction during exposure of $\mathrm{PuO}_{2}$ to a 2:1 $\mathrm{D}_{2}: \mathrm{O}_{2}$ mixture at $24.5^{\circ} \mathrm{C}$. Values of $\mathrm{R}$ and $\mathrm{P}$ are listed in Table 1. 


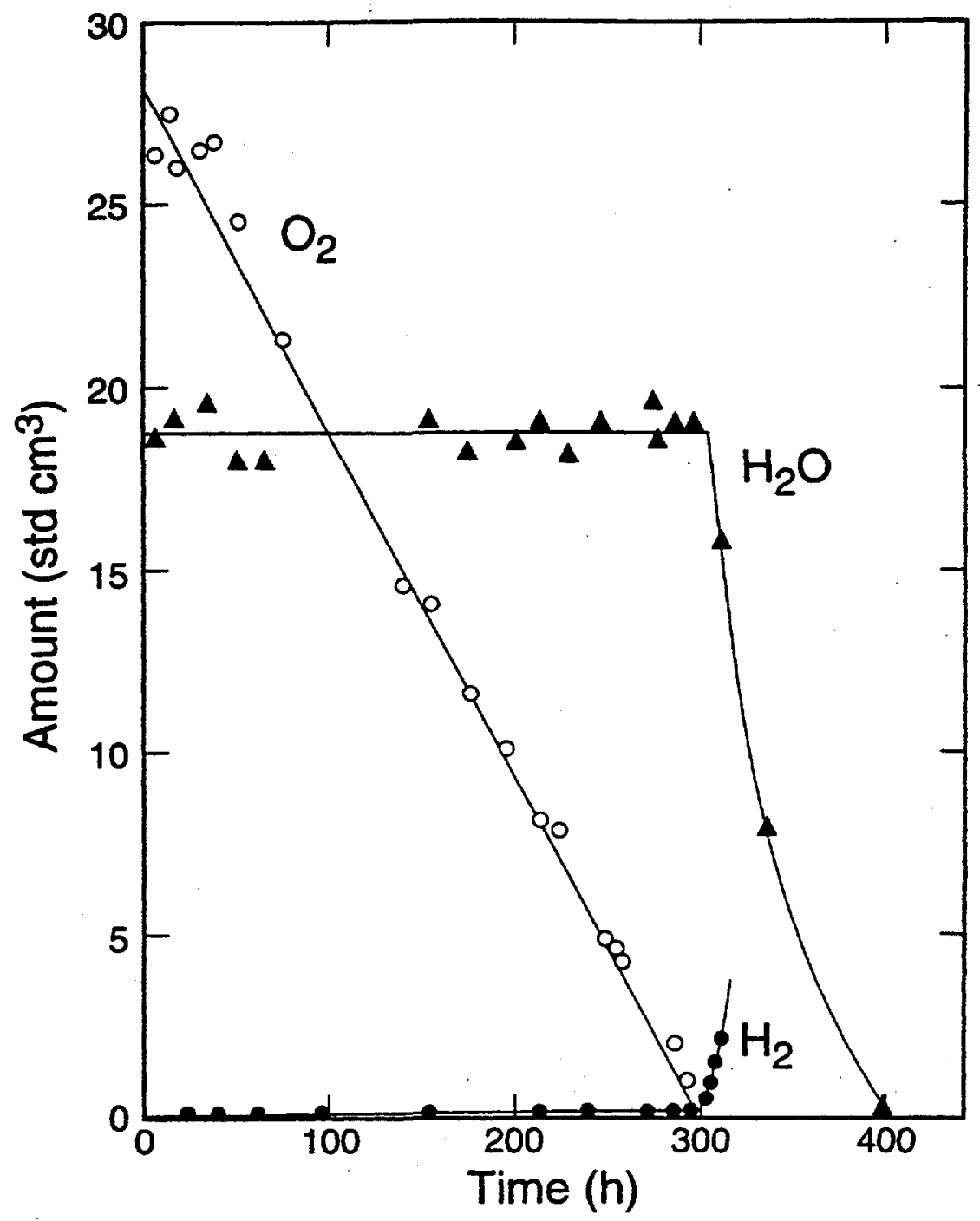

Figure 4. Time dependence of constituents in the gas phase during reaction of uranium metal with a 3:2 $\mathrm{O}_{2}: \mathrm{H}_{2} \mathrm{O}$ mixture at $100^{\circ} \mathrm{C}$. The data are from the report by $\mathrm{McD}$. Baker, Ness, and Orman (Reference 24). 